\title{
The Effect of Sitagliptin on the Regression of Carotid Intima-Media Thickening in Patients with Type 2 Diabetes Mellitus: A Post Hoc Analysis of the Sitagliptin Preventive Study of Intima-Media Thickness Evaluation
}

\author{
Tomoya Mita, ${ }^{1}$ Naoto Katakami, ${ }^{2,3}$ Toshihiko Shiraiwa, ${ }^{4}$ Hidenori Yoshii, ${ }^{5}$ \\ Masahiko Gosho, ${ }^{6}$ Iichiro Shimomura, ${ }^{2}$ and Hirotaka Watada ${ }^{1}$ \\ ${ }^{1}$ Department of Metabolism and Endocrinology, Juntendo University Graduate School of Medicine, Hongo 2-1-1, Bunkyo-ku, \\ Tokyo 113-8421, Japan \\ ${ }^{2}$ Department of Metabolic Medicine, Osaka University Graduate School of Medicine, 2-2 Yamadaoka, Suita, Osaka 565-0871, Japan \\ ${ }^{3}$ Department of Metabolism \& Atherosclerosis, Osaka University Graduate School of Medicine, 2-2 Yamadaoka, Suita, \\ Osaka 565-0871, Japan \\ ${ }^{4}$ Shiraiwa Medical Clinic, 4-10-24 Houzenji, Kashiwara, Osaka 582-0005, Japan \\ ${ }^{5}$ Department of Medicine, Diabetology \& Endocrinology, Juntendo Tokyo Koto Geriatric Medical Center, Shinsuna 3-3-20, Koto-ku, \\ Tokyo 136-0075, Japan \\ ${ }^{6}$ Department of Clinical Trial and Clinical Epidemiology, Faculty of Medicine, University of Tsukuba, 1-1-1 Tennodai, Tsukuba, \\ Ibaraki 305-8575, Japan
}

Correspondence should be addressed to Tomoya Mita; tom-m@juntendo.ac.jp

Received 1 October 2016; Accepted 24 November 2016; Published 17 January 2017

Academic Editor: Michael Horowitz

Copyright (C) 2017 Tomoya Mita et al. This is an open access article distributed under the Creative Commons Attribution License, which permits unrestricted use, distribution, and reproduction in any medium, provided the original work is properly cited.

\begin{abstract}
Background. The effect of dipeptidyl peptidase-4 (DPP-4) inhibitors on the regression of carotid IMT remains largely unknown. The present study aimed to clarify whether sitagliptin, DPP-4 inhibitor, could regress carotid intima-media thickness (IMT) in insulin-treated patients with type 2 diabetes mellitus (T2DM). Methods. This is an exploratory analysis of a randomized trial in which we investigated the effect of sitagliptin on the progression of carotid IMT in insulin-treated patients with T2DM. Here, we compared the efficacy of sitagliptin treatment on the number of patients who showed regression of carotid IMT of $\geq 0.10 \mathrm{~mm}$ in a post hoc analysis. Results. The percentages of the number of the patients who showed regression of mean-IMT-CCA (28.9\% in the sitagliptin group versus $16.4 \%$ in the conventional group, $P=0.022)$ and left max-IMT-CCA ( $43.0 \%$ in the sitagliptin group versus $26.2 \%$ in the conventional group, $P=0.007$ ), but not right max-IMT-CCA, were higher in the sitagliptin treatment group compared with those in the non-DPP-4 inhibitor treatment group. In multiple logistic regression analysis, sitagliptin treatment significantly achieved higher target attainment of mean-IMT-CCA $\geq 0.10 \mathrm{~mm}$ and right and left max-IMT-CCA $\geq 0.10 \mathrm{~mm}$ compared to conventional treatment. Conclusions. Our data suggested that DPP-4 inhibitors were associated with the regression of carotid atherosclerosis in insulin-treated T2DM patients. This study has been registered with the University Hospital Medical Information Network Clinical Trials Registry (UMIN000007396).
\end{abstract}

\section{Background}

Type 2 diabetes mellitus (T2DM) is a risk factor for cardiovascular disease (CVD). Recent studies have cast doubt on the benefits of strict glycemic control on CVD in patients with advanced atherosclerosis or longstanding T2DM [1-3]. Particularly, strict glycemic control using intensive insulin therapy increases the risk of hypoglycemia [4] and weight gain [5] which might reduce their beneficial effects. Therefore, a reduction in insulin dose by stimulation of endogenous 
glucose responsive insulin secretion and increased insulin sensitivity using oral hypoglycemic agents (OHA) may reduce these adverse effects of insulin therapy and be a promising strategy to prevent the progression of atherosclerosis.

The carotid artery intima-media thickness (IMT) and its progression are considered a marker of progression of atherosclerosis. Recent studies demonstrated that add-on therapy of metformin [6] or pioglitazone [7] to insulin therapy did not slow down the progression of carotid IMT compared with control group in patients with T2DM. On the other hand, we recently reported that treatment with sitagliptin, a dipeptidyl peptidase-4 (DPP-4) inhibitor, attenuated the progression of carotid IMT in insulin-treated patients with T2DM compared with the conventional treatment without increasing the risk of hypoglycemia [8].

Previous studies demonstrated that several therapies for cardiovascular risk factors including statin could regress carotid IMT in patients with T2DM [9-12]. However, the effect of DPP-4 inhibitors on the regression of carotid IMT remains largely unknown. In this study, we investigated whether sitagliptin has beneficial effect on regressing carotid IMT in a post hoc analysis while the original article focused on investigating the effects of sitagliptin on IMT progression.

\section{Methods}

2.1. Study Population. We performed a post hoc analysis from the Sitagliptin Preventive Study of Intima-Media Thickness Evaluation (SPIKE). The study design, inclusion and exclusion criteria, study schedule, and measurements were described in detail previously [8]. Briefly, insulin-treated Japanese T2DM patients, free of past history of apparent CVD, who periodically attended the outpatient diabetes clinics at 12 centers across Japan were asked to participate in this study. Randomization was performed using a dynamic allocation method based on the number of times of insulin injection, with/without pioglitazone, age, and gender. A total of 282 participants were randomly allocated to either the sitagliptin group ( $n=142$ ) or the conventional treatment group (using drugs other than the DPP-4 inhibitor) $(n=140)$. Finally, 137 in the sitagliptin group and 137 in the conventional treatment group were included in the full analysis set. Each participant underwent ultrasonography of the carotid arteries performed by expert sonographers at the start of the study, and the procedure was repeated after 52 and 104 weeks as reported previously [8]. To avoid interreader variability, all scans were electronically stored and emailed to the central office (IMT Evaluation Committee, Osaka, Japan) to be read by a single experienced reader blinded to the clinical characteristics of the patients, in a random order, using automated digital edge-detection software (Intimascope; MediaCross, Tokyo, Japan). The software system averages about 200 points of IMT values in the segment $2 \mathrm{~cm}$ proximal to the dilation of the carotid bulb (mean-IMT-CCA). The greatest thicknesses of IMT, including plaque lesions in the common carotid arteries (max-IMT-CCA), were also measured separately. The reproducibility of IMT measurement was very high as described previously [8]. Carotid IMT regression was defined as a decrease of $\geq 0.10 \mathrm{~mm}$ in
mean-IMT-CCA, right max-IMT-CCA, and left max-IMTCCA at the end of the study from the baseline.

2.2. Statistical Analysis. Data were reported as mean \pm standard deviation. The number and percentage of patients who achieved the regression of IMT $\geq 0.10 \mathrm{~mm}$ from the baseline at the end of the study regression were presented using Fisher's exact test. Multiple logistic regression analysis was performed to compare target attainment of IMT $\geq 0.10 \mathrm{~mm}$ from the baseline at the end of the study between the two groups. Classical atherosclerotic risk factors based on clinical judgment were included in the model. Adjusted odds ratio (OR) estimates and Wald 95\% confidence interval (CI) were calculated. Multivariate logistic regression models were used to identify the factors for regression of IMT $\geq 0.10 \mathrm{~mm}$ from the baseline at the end of the study. Classical atherosclerotic risk factors and changes in some of them based on clinical judgment were included in the model. All statistical tests were two-sided with 5\% significance level. All analyses were performed using the SAS software version 9.4 (SAS Institute, Cary, NC).

\section{Results}

3.1. Baseline Clinical Characteristics and the Results of the Original Article. As described previously [8], baseline clinical characteristics including potential risk factors for carotid atherosclerosis were comparable between the groups (Table 1). The mean age was about 64 years, about $60 \%$ male, and $\mathrm{HbA1c}$ was about $8 \%$ and the estimated diabetes duration was about 17 years. Lipids and blood pressure of study subjects were relatively well controlled. A total of 282 participants were randomly allocated to either the sitagliptin group ( $n=142$ ) or the conventional treatment group (using drugs other than the DPP-4 inhibitor) $(n=140)$. Finally, 137 in the sitagliptin group and 137 in the conventional treatment group were included in the full analysis set (Figure 1). Changes in the mean $(-0.053 \mathrm{~mm}(-0.090,-0.016)$ (mean change; $95 \% \mathrm{CI}), P=0.005$, by one-sample $t$-test based on mixed effects model for repeated measures) and left maximum IMT $(-0.087 \mathrm{~mm}(-0.161,-0.014), P=0.021)$, but not right maximum IMT $(-0.033 \mathrm{~mm}(-0.121,0.054), P=0.45)$, of the common carotid arteries were significantly greater after sitagliptin treatment compared with conventional treatment (Table 2). Also, the improvement in HbA1c was significantly greater in the sitagliptin group than in the conventional group (Table 2). On the other hand, there were no differences between the two groups in other risk factors such as BP, the lipid parameters at baseline, or their changes during the observation period (Table 2).

\subsection{The Percentage of Patients Achieving IMT Regression.} In this study, we compared the percentage of patients who achieved a decrease of $\geq 0.10 \mathrm{~mm}$ in mean-IMT-CCA and right and left max-IMT-CCA at the end of the study. The percentages of patients with regression of mean-IMTCCA $(28.9 \%$ in the sitagliptin group versus $16.4 \%$ in the conventional group, $P=0.022$ ) and left max-IMT-CCA $(43.0 \%$ in the sitagliptin group versus $26.2 \%$ in the conventional group, $P=0.007)$ were higher in the sitagliptin 
TABLE 1: Clinical characteristics of patients of the two groups.

\begin{tabular}{|c|c|c|c|}
\hline Parameters & Sitagliptin group $(n=137)$ & Conventional group $(n=137)$ & $P$ value \\
\hline Age (years) & $63.8 \pm 9.7$ & $63.6 \pm 1.0$ & 0.90 \\
\hline Gender (males) (\%) & $83(61)$ & $82(60)$ & 1.00 \\
\hline Body mass index & $25.0 \pm 4.3$ & $25.0 \pm 3.8$ & 0.88 \\
\hline Current smoking & $30(22)$ & $29(21)$ & 0.22 \\
\hline Duration of diabetes (years) & $17.2 \pm 8.5$ & $17.3 \pm 8.7$ & 0.94 \\
\hline $\mathrm{HbAlc}$ at baseline $(\mathrm{mmol} / \mathrm{mol})$ & $64.9 \pm 11.9$ & $63.9 \pm 10.6$ & 0.45 \\
\hline Systolic blood pressure (mmHg) & $130 \pm 16$ & $132 \pm 14$ & 0.88 \\
\hline Total cholesterol at baseline $(\mathrm{mmol} / \mathrm{l})$ & $5.02 \pm 0.91$ & $4.94 \pm 0.86$ & 0.50 \\
\hline HDL cholesterol at baseline $(\mathrm{mmol} / \mathrm{l})$ & $1.46 \pm 0.37$ & $1.39 \pm 0.38$ & 0.14 \\
\hline Triglyceride at baseline $(\mathrm{mmol} / \mathrm{l})$ & $1.13(0.83,1.55)$ & $1.17(0.90,1.72)$ & 0.22 \\
\hline $\mathrm{eGFR}\left(\mathrm{ml} / \mathrm{min} / 1.73 \mathrm{~m}^{2}\right)$ & $77.7 \pm 21.2$ & $79.7 \pm 24.2$ & 0.47 \\
\hline Mean IMT $(\mathrm{mm})$ & $0.84 \pm 0.19$ & $0.84 \pm 0.21$ & 0.81 \\
\hline Right maximum IMT (mm) & $1.04 \pm 0.29$ & $1.06 \pm 0.40$ & 0.69 \\
\hline Left maximum IMT (mm) & $1.10 \pm 0.32$ & $1.11 \pm 0.41$ & 0.87 \\
\hline \multicolumn{4}{|l|}{ Use of oral glucose-lowering agents } \\
\hline Metformin & $49(36)$ & $48(35)$ & 1.00 \\
\hline Sulfonylurea & $17(12)$ & $15(11)$ & 0.85 \\
\hline Glinides & $2(1)$ & $19(14)$ & $<0.001$ \\
\hline Thiazolidinediones & $13(9)$ & $11(8)$ & 0.83 \\
\hline$\alpha$-Glucosidase inhibitor & $41(30)$ & $42(31)$ & 1.00 \\
\hline \multicolumn{4}{|l|}{ Others } \\
\hline Angiotensin-converting enzyme inhibitors & $8(6)$ & $4(3)$ & 0.59 \\
\hline Angiotensin II receptor blockers & $53(39)$ & $69(50)$ & 0.07 \\
\hline Statins & $66(48)$ & $63(46)$ & 0.81 \\
\hline Antiplatelet agents & $29(21)$ & $30(22)$ & 1.00 \\
\hline
\end{tabular}

Data are number (\%) of patients or mean \pm SD values.

IMT, intima-media thickness; eGFR, glomerular filtration rate.

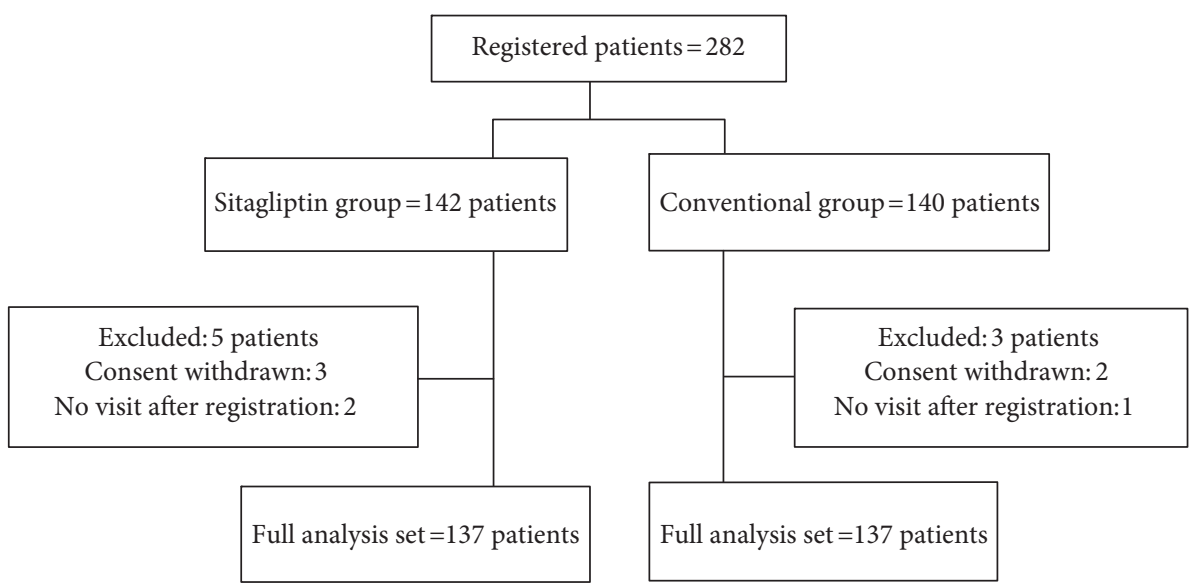

FIgURE 1: Trial schema.

treatment group compared with those in the conventional treatment group. Also, the percentage in the right max-IMTCCA tended to be higher in the sitagliptin treatment group compared with that in the conventional treatment group $(38.3 \%$ in the sitagliptin group versus $27.9 \%$ in the conventional group, $P=0.10$ ). Multiple logistic regression analysis that included the treatment group, age, gender, and baseline IMT (model 1) demonstrated that sitagliptin treatment significantly achieved higher target attainment of mean-IMT $\geq 0.10 \mathrm{~mm}$ and right and left max-IMT-CCA 
TABLE 2: Effects of sitagliptin on glucose metabolism, blood pressure lipid metabolism, and IMT.

\begin{tabular}{|c|c|c|c|}
\hline Parameters & Sitagliptin group $(n=137)$ & Conventional group $(n=137)$ & $P$ value \\
\hline \multicolumn{4}{|l|}{$\mathrm{HbAlc}$ at baseline $(\mathrm{mmol} / \mathrm{mol})$} \\
\hline 104 weeks (change from baseline) & $-5.6 \pm 11.4$ & $-2.2 \pm 10.0$ & 0.004 \\
\hline \multicolumn{4}{|l|}{ Systolic blood pressure (mmHg) } \\
\hline 104 weeks (change from baseline) & $0 \pm 19$ & $3 \pm 17$ & 0.20 \\
\hline \multicolumn{4}{|l|}{ Total cholesterol at baseline $(\mathrm{mmol} / \mathrm{l})$} \\
\hline 104 weeks (\% change from baseline) & $-2.7 \pm 15.6$ & $-1.8 \pm 14.6$ & 0.63 \\
\hline \multicolumn{4}{|l|}{ HDL cholesterol at baseline (mmol/l) } \\
\hline 104 weeks (\% change from baseline) & $0.2 \pm 15.2$ & $-0.5 \pm 14.7$ & 0.74 \\
\hline \multicolumn{4}{|l|}{ Triglyceride at baseline $(\mathrm{mmol} / \mathrm{l})$} \\
\hline 104 weeks (\% change from baseline) & $0.0(-25.1,44.6)$ & $-1.6(-24.6,16.7)$ & 0.35 \\
\hline \multicolumn{4}{|l|}{ Mean IMT $(\mathrm{mm})$} \\
\hline 104 weeks (change from baseline) & $-0.03 \pm 0.17$ & $0.02 \pm 0.14$ & 0.008 \\
\hline \multicolumn{4}{|l|}{ Right maximum IMT } \\
\hline 104 weeks (change from baseline) & $0.00 \pm 0.35$ & $0.02 \pm 0.37$ & 0.67 \\
\hline \multicolumn{4}{|l|}{ Left maximum IMT } \\
\hline 104 weeks (change from baseline) & $-0.06 \pm 0.34$ & $0.02 \pm 0.29$ & 0.033 \\
\hline
\end{tabular}

Data are mean \pm SD or median (range) values. Differences in parameters from baseline to 104 weeks between groups were analyzed by the Student $t$-test or Wilcoxon's rank sum test. IMT, intima-media thickness.

$\geq 0.10 \mathrm{~mm}$ compared to conventional treatment (Table 3). Similar findings were noted even in the adjusted models, including model 2 (model $1+$ body mass index + current smoking); model 3 (model $2+$ HbAlc, total cholesterol, high-density lipoprotein cholesterol, triglyceride, and systolic blood pressure); model 4 (model $3+$ estimated glomerular filtration rate + angiotensin-converting enzyme/angiotensin II receptor blocker, statin, and antiplatelets); and model 5 (model $4+\mathrm{OHA}$ ).

3.3. Predictive Factors for Regression of IMT. Next, multivariate logistic regression models were performed to identify predictive factors for regression of mean-IMT-CCA and right and left max-IMT-CCA. Sitagliptin treatment and higher IMT at baseline were mainly associated with the regression of carotid IMT (Table 4).

\section{Discussion}

Previous study demonstrated that aggressive lipid-lowering therapies with a statin alone or statin and ezetimibe resulted in regression of carotid IMT in patients with T2DM [9]. Theoretically, statin reversed carotid atherosclerosis through reductions in the lipid, inflammation and oxidative stress, and changes in tissue characteristic of plaque. With respect to OHA, previous studies showed that pioglitazone treatment led to the regression of carotid IMT in patient with T2DM probably through a multitude of mechanisms, including improvement in several metabolic factors and insulin sensitivity, anti-inflammatory effect, and direct actions on the vascular cells $[10,11]$. In addition, modulation in postprandial hyperglycemia with repaglinide was reported to be associated with the reduction in carotid IMT in patients with T2DM [12]. However, ongoing background treatments
TABLE 3: Results of adjustment randomized comparisons.

\begin{tabular}{lcc}
\hline & Adjusted odds ratio (95\% CI) & $P$ value \\
\hline Model 1 & Mean intima-media thickness & \\
Model 2 & $2.29(1.17-4.47)$ & 0.015 \\
Model 3 & $2.27(1.16-4.44)$ & 0.016 \\
Model 4 & $2.48(1.24-4.93)$ & 0.010 \\
Model 5 & $2.60(1.29-5.28)$ & 0.008 \\
& $2.89(1.34-6.24)$ & 0.007 \\
Model 1 & $1.77(1.00-3.13)$ & \\
Model 2 & $1.78(1.00-3.14)$ & 0.049 \\
Model 3 & $1.87(1.04-3.34)$ & 0.049 \\
Model 4 & $1.88(1.05-3.40)$ & 0.036 \\
Model 5 & $2.15(1.12-4.14)$ & 0.035 \\
& Left maximum intima-media thickness & 0.022 \\
Model 1 & $2.22(1.25-3.92)$ & 0.006 \\
Model 2 & $2.24(1.26-3.98)$ & 0.006 \\
Model 3 & $2.33(1.28-4.22)$ & 0.006 \\
Model 4 & $2.43(1.32-4.48)$ & 0.004 \\
Model 5 & $2.46(1.28-4.73)$ & 0.007 \\
\hline
\end{tabular}

Multiple logistic regression analysis included the treatment group, age, gender, and baseline IMT (model 1); model 1 plus body mass index and current smoking (model 2); model 2 plus HbAlc, total cholesterol, high-density lipoprotein cholesterol, triglyceride, and systolic blood pressure (model 3); model 3 plus eGFR, use of angiotensin-converting enzyme/angiotensin II receptor blocker, use of statin, and use of antiplatelets (model 4); model 4 plus the use of oral hypoglycemic agents (model 5).

with those drugs at baseline, not add-on therapies, did not have major impact on the regression of carotid IMT in this study (Table 4). The effects of these drugs may have already attributed to reduced carotid IMT although we did not collect the 
TABLE 4: Results of multivariate logistic regression models for the regression of IMT of $\geq 0.10 \mathrm{~mm}$ from baseline at the end of the study.

\begin{tabular}{|c|c|c|c|c|c|c|}
\hline \multirow[b]{2}{*}{ Factor } & \multicolumn{2}{|l|}{ Mean IMT } & \multicolumn{2}{|l|}{ Right max IMT } & \multicolumn{2}{|l|}{ Left max IMT } \\
\hline & $\begin{array}{l}\text { Adjusted odds ratio } \\
\text { (95\% CI) }\end{array}$ & $P$ value & $\begin{array}{l}\text { Adjusted odds ratio } \\
\text { (95\% CI) }\end{array}$ & $P$ value & $\begin{array}{l}\text { Adjusted odds ratio } \\
\qquad(95 \% \mathrm{CI})\end{array}$ & $P$ value \\
\hline Age (1 year) & $1.01(0.95-1.06)$ & 0.83 & $0.98(0.94-1.02)$ & 0.37 & $1.01(0.97-1.06)$ & 0.61 \\
\hline Gender (male/female) & $1.99(0.83-4.79)$ & 0.12 & $0.67(0.33-1.35)$ & 0.26 & $1.02(0.49-2.14)$ & 0.95 \\
\hline Body mass index $\left(1 \mathrm{~kg} / \mathrm{m}^{2}\right)$ & $1.07(0.95-1.20)$ & 0.26 & $1.03(0.94-1.13)$ & 0.56 & $1.00(0.91-1.10)$ & 0.98 \\
\hline Estimated duration of diabetes ( 1 year) & $1.02(0.97-1.07)$ & 0.42 & $0.99(0.95-1.03)$ & 0.65 & $1.02(0.98-1.07)$ & 0.26 \\
\hline Smoking (yes/no) & $1.93(0.67-5.52)$ & 0.22 & $0.72(0.30-1.74)$ & 0.47 & $1.83(0.77-4.35)$ & 0.17 \\
\hline $\mathrm{HbA} 1 \mathrm{c}(1 \mathrm{mmol} / \mathrm{l})$ & $1.04(0.69-1.56)$ & 0.87 & $1.07(0.76-1.51)$ & 0.68 & $1.00(0.70-1.44)$ & 0.99 \\
\hline Systolic BP (1 mmHg) & $0.99(0.96-1.02)$ & 0.40 & $1.03(1.01-1.06)$ & 0.012 & $0.97(0.94-0.99)$ & 0.02 \\
\hline Total cholesterol ( $1 \mathrm{mmol} / \mathrm{l})$ & $0.64(0.35-1.18)$ & 0.16 & $1.11(0.69-1.79)$ & 0.68 & $1.19(0.72-1.95)$ & 0.49 \\
\hline HDL cholesterol ( $1 \mathrm{mmol} / \mathrm{l})$ & $0.44(0.11-1.78)$ & 0.25 & $1.19(0.38-3.75)$ & 0.76 & $0.69(0.22-2.15)$ & 0.52 \\
\hline Triglyceride (1 mmol/l) & $0.92(0.58-1.44)$ & 0.71 & $0.87(0.59-1.29)$ & 0.5 & $1.00(0.72-1.38)$ & 1.00 \\
\hline eGFR $\left(1 \mathrm{ml} / \mathrm{min} / 1.73 \mathrm{~m}^{2}\right)$ & $1.01(0.99-1.03)$ & 0.27 & $1.00(0.98-1.01)$ & 0.74 & $1.01(0.99-1.03)$ & 0.22 \\
\hline Baseline cIMT $(0.01 \mathrm{~mm})$ & $1.05(1.03-1.08)$ & $<0.001$ & $1.02(1.01-1.03)$ & $<0.001$ & $1.02(1.01-1.03)$ & $<0.001$ \\
\hline $\begin{array}{l}\text { Treatment group (sitagliptin } \\
\text { treatment/conventional treatment) }\end{array}$ & $3.58(1.60-7.99)$ & 0.002 & $2.02(1.07-3.84)$ & 0.031 & $2.38(1.23-4.58)$ & 0.01 \\
\hline ACE/ARB (yes/no) & $1.10(0.50-2.45)$ & 0.81 & $0.86(0.45-1.68)$ & 0.67 & $1.31(0.66-2.63)$ & 0.44 \\
\hline Statins (yes/no) & $0.76(0.33-1.74)$ & 0.51 & $1.27(0.64-2.49)$ & 0.49 & $0.88(0.44-1.76)$ & 0.72 \\
\hline Antiplatelets (yes/no) & $0.34(0.12-0.96)$ & 0.04 & $0.79(0.35-1.79)$ & 0.57 & $0.40(0.17-0.97)$ & 0.042 \\
\hline OHA (yes/no) & $0.55(0.26-1.18)$ & 0.12 & $0.83(0.43-1.58)$ & 0.56 & $0.53(0.27-1.04)$ & 0.064 \\
\hline $\begin{array}{l}\text { Changes in systolic BP at } 104 \text { weeks } \\
\text { from baseline }(1 \mathrm{mmHg})\end{array}$ & $1.00(0.98-1.03)$ & 0.94 & $1.02(1.00-1.04)$ & 0.079 & $0.99(0.97-1.01)$ & 0.45 \\
\hline $\begin{array}{l}\text { Changes in } \mathrm{HbAlc} \text { at } 104 \text { weeks from } \\
\text { baseline }(1 \mathrm{mmol} / \mathrm{l})\end{array}$ & $1.25(0.84-1.87)$ & 0.27 & $1.13(0.80-1.60)$ & 0.49 & $0.91(0.64-1.29)$ & 0.59 \\
\hline $\begin{array}{l}\text { Changes in total cholesterol at } 104 \text { weeks } \\
\text { from baseline }(1 \mathrm{mmol} / \mathrm{l})\end{array}$ & $0.97(0.94-1.00)$ & 0.051 & $0.99(0.97-1.02)$ & 0.45 & $0.99(0.96-1.01)$ & 0.30 \\
\hline $\begin{array}{l}\text { Changes in HDL cholesterol at } 104 \text { weeks } \\
\text { from baseline }(1 \mathrm{mmol} / \mathrm{l})\end{array}$ & $1.00(0.97-1.02)$ & 0.76 & $1.01(0.99-1.03)$ & 0.33 & $1.01(0.98-1.03)$ & 0.59 \\
\hline $\begin{array}{l}\text { Changes in triglyceride at } 104 \text { weeks from } \\
\text { baseline }(1 \mathrm{mmol} / \mathrm{l})\end{array}$ & $1.00(0.99-1.00)$ & 0.39 & $1.00(1.00-1.01)$ & 0.22 & $1.00(0.99-1.01)$ & 0.85 \\
\hline
\end{tabular}

Multivariate logistic regression models were used to identify the determination of the regression of IMT of $\geq 0.10 \mathrm{~mm}$ from baseline at the end of the study. $\mathrm{ACE} / \mathrm{ARB}$, angiotensin-converting enzyme/angiotensin II receptor blocker; BP, blood pressure; IMT, intima-media thickness; eGFR, glomerular filtration rate; OHA, oral hypoglycemic agents.

data about the treatment periods. Furthermore, sitagliptin treatment was still associated with and was an independent predictive factor for the regression of carotid IMT even considering several possible risk factors for atherosclerosis, background therapies which may have antiatherosclerotic effects, and/or changes in metabolic parameters. Although the exact mechanism by which DPP-4 inhibitors induce the regression of carotid IMT remains uncertain at present, the differences in carotid IMT progression could not be explained by the difference in $\mathrm{HbA} 1 \mathrm{c}$ as we discussed in the original article [8]. The glucagon-like peptide-1 dependent and/or independent effect of DPP-4 inhibitors on the vascular wall may attribute to reduced atherosclerosis [13-16].

There are several certain limitations. First, because the limit of detection of IMT measured by ultrasound scanner used in this study was $<0.1 \mathrm{~mm}$, we defined a decrease of $\geq 0.10 \mathrm{~mm}$ in IMT as IMT regression in terms of measurement sensitivity in these exploratory post hoc analyses. There are very few studies to investigate the effect of drugs on IMT regression. In a previous study, IMT regression was defined as a decrease of $>0.020 \mathrm{~mm}$ in mean IMT without reasonable scientific grounds [12]. Whether these magnitudes of IMT regression are clinically relevant still remained unclear. Thus, it may be important to identify the magnitude of IMT regression that is associated with the incidence of CVD. In this regard, we are conducting a study to follow up the incidence of CVD in the same cohort. We will quantitatively assess the relationship between the incidence of CVD and IMT regression. Second, these were exploratory analyses with the concern of multiplicity of statistical testing. These factors allow increased risk for false-negative and false-positive significance results. Thus, the findings should be interpreted with caution.

\section{Conclusions}

In conclusion, our data suggested that DPP-4 inhibitors were associated with the regression of carotid atherosclerosis in insulin-treated T2DM patients free of apparent CVD. 


\section{Abbreviations}

$\begin{array}{ll}\text { CI: } & \text { Confidence interval } \\ \text { CVD: } & \text { Cardiovascular disease } \\ \text { DPP-4: } & \text { Dipeptidyl peptidase-4 } \\ \text { IMT: } & \text { Intima-media thickness } \\ \text { Max-IMT-CCA: } & \begin{array}{l}\text { Maximum IMT of the common } \\ \text { carotid artery }\end{array} \\ \text { Mean-IMT-CCA: } & \text { Mean IMT of the common } \\ & \text { carotid artery } \\ \text { OHA: } & \text { Oral hypoglycemic agents } \\ \text { OR: } & \text { Odds ratio } \\ \text { SPIKE: } & \text { Sitagliptin Preventive Study of } \\ \text { T2DM: } & \text { Intima-Media Thickness Evaluation } \\ & \text { Type 2 diabetes mellitus. }\end{array}$

\section{Ethical Approval}

This protocol was approved by the Institutional Review Board of each participating institution (Jiyugaoka Medical Clinic, Juntendo Tokyo Koto Geriatric Medical Center, Juntendo University Graduate School of Medicine, Kansai Rosai Hospital, Naka Memorial Clinic, Osaka General Medical Center, Osaka Police Hospital, Osaka University Graduate School of Medicine, and Sasebo Chuo Hospital) in compliance with the Declaration of Helsinki and current legal regulations in Japan.

\section{Consent}

Written informed consent was obtained from all the participants after full explanation of the study.

\section{Disclosure}

The funder had no role in study design, data collection and analysis, decision to publish, or preparation of the manuscript.

\section{Competing Interests}

Tomoya Mita received research funds from MSD and Takeda Pharma K.K. and has received lecture fees from AstraZeneca K.K., Boehringer Ingelheim, Eli Lilly, Kowa Pharmaceutical Co., Mitsubishi Tanabe Pharma Co., MSD, Ono Pharmaceutical Co., and Takeda Pharmaceutical Co. Naoto Katakami is a staff member of the endowed chair (Department of Metabolism and Atherosclerosis) established by funds from Kowa Pharmaceutical Co. and has received research funds from MSD and lecture fees from Astellas Pharma Inc., AstraZeneca K.K., Boehringer Ingelheim, Daiichi Sankyo Inc., Dainippon Sumitomo Pharma Co., Eisai Co., Eli Lilly, Kowa Pharmaceutical Co., Mitsubishi Tanabe Pharma Co., Novartis Pharmaceuticals, Novo Nordisk Pharma, Ono Pharmaceutical Co., Otsuka Pharmaceutical, Shionogi \& Co., Takeda Pharmaceutical Co., Sanofi-Aventis, and Shionogi \& Co. Toshihiko Shiraiwa has received lecture fees from Boehringer Ingelheim, Sanofi-Aventis, Novo Nordisk Pharma, Novartis Pharmaceuticals, Eli Lilly, Abbott Japan, Takeda Pharmaceutical Co., Sanwa Kagaku Kenkyusho Co. Ltd., Mitsubishi Tanabe Pharma Co., Daiichi Sankyo Inc., Astellas Pharma Inc., Ono PharmaceuticalCo., MSD, Shionogi,
Pharma, and Taisho Toyama Pharmaceutical Co. Masahiko Gosho received lecture fees from Novartis and Tiho Pharma K.K., received travel fees from Takeda Pharmaceutical Co., and received manuscript fee from Kowa Co., Ltd. Iichiro Shimomura has received lecture fees from Astellas Pharma Inc., AstraZeneca K.K., MSD K.K., Ono Pharmaceutical Co., Kyowa Hakko Kirin Co., Ltd., Kowa Pharmaceutical Co., Sanofi K.K., Sanwa Kagaku Kenkyusho Co., Ltd., Daiichi Sankyo Co., Takeda Pharma K.K., Mitsubishi Tanabe Pharma Co., Teijin Pharma, Eli Lilly Japan K.K., Nippon Boehringer Ingelheim Co., Novartis Pharma K.K., Novo Nordisk Pharma, Bayer Yakuhin, Pfizer Japan Inc., Bristol-Myers K.K., Mochida Pharmaceutical Co., Shionogi \& Co., Taisho Toyama Pharmaceutical Co., and Shionogi \& Co. and research funds from Astellas Pharma Inc., AstraZeneca K.K., Eisai Co., MSD K.K., Otsuka Pharmaceutical Co., Ono Pharmaceutical Co., Kaken Pharmaceutical Co., Kissei Pharmaceutical Co., Kyowa Hakko Kirin Co., Ltd., Sanofi K.K., Shionogi \& Co., Daiichi Sankyo Co., Dainippon Sumitomo Pharma Co., Takeda Pharma K.K., Mitsubishi Tanabe Pharma Co., Teijin Pharma, Nippon Boehringer Ingelheim Co., Novartis Pharma K.K., Novo Nordisk Pharma, Pfizer Japan Inc., Bristol-Myers K.K., Mochida Pharmaceutical Co., Eli Lilly Japan K.K., Kowa Co., Ltd., Kowa Pharmaceutical Co., and Taisho Toyama Pharmaceutical Co. Hirotaka Watada has received lecture fees from Novo Nordisk, Inc., Eli Lilly and Company, Sanofi, Dainippon Sumitomo Pharma Co., Fujifilm, Bayer Health Care, Kissei Pharmaceutical Company, Mochida Pharmaceutical Company, MSD, Takeda Pharmaceutical Company, Boehringer Ingelheim Pharmaceuticals, Inc., Daiichi-Sankyo, Ono Pharmaceutical Co., Ltd., Novartis Pharmaceuticals Corporation, Mitsubishi Tanabe Pharma Corporation, AstraZeneca LP, Kyowa Hakko Kirin Co., Ltd., Sanwa Kagaku Kenkyusho Co., Ltd., Kowa Company Ltd., and Astellas Pharma, Inc., advisory fees from Novo Nordisk, Inc., Mochida Pharma Company, AstraZeneca LP, Kowa Company, Astellas Pharma, Inc., Sanofi, Boehringer Ingelheim Pharmaceuticals, Inc., MSD, Mitsubishi Tanabe Pharma Corporation, Novartis Pharmaceuticals Corporation, Dainippon Sumitomo Pharma Co., Takeda Pharmaceutical Company, Ono Pharmaceutical Co., Pfizer, Inc., and Kowa Company, and research funds from Boehringer Ingelheim, Pfizer, Mochida Pharmaceutical Co., Sanofi-Aventis, Novo Nordisk Pharma, Novartis Pharmaceuticals, Sanwa Kagaku Kenkyusho Co., Ltd., Terumo Corp., Eli Lilly, Mitsubishi Tanabe Pharma, Daiichi Sankyo Inc., Takeda Pharmaceutical Co., MSD, Shionogi, Pharma, Dainippon Sumitomo Pharma, Kissei Pharma, and AstraZeneca.

\section{Authors' Contributions}

The authors meet the criteria for authorship recommended by the International Committee of Medical Journal Editors and take full responsibility for all contents of the manuscript and editorial decisions. Tomoya Mita, Naoto Katakami, Toshihiko Shiraiwa, Hidenori Yoshii, Masahiko Gosho, Iichiro Shimomura, and Hirotaka Watada contributed to the study design and were involved in all stages of manuscript development. Tomoya Mita and Naoto Katakami drafted the manuscript. Masahiko Gosho contributed to the analysis 
of research data. Tomoya Mita, Naoto Katakami, Toshihiko Shiraiwa, Hidenori Yoshii, Masahiko Gosho, Iichiro Shimomura, and Hirotaka Watada were involved in the analysis and interpretation of data, reviewed/edited the manuscript, and approved the final manuscript. Iichiro Shimomura and Hirotaka Watada were the principal guarantors of this work and have full access to all the data and take responsibility for the integrity of the data and accuracy of data analysis.

\section{Acknowledgments}

Authors acknowledge the SPIKE trial site investigators listed (in alphabetical order) as follows. The SPIKE study is a multicenter collaboration. In addition to the listed authors, the following SPIKE study investigators were involved in this study: Jiyugaoka Medical Clinic: Hiroki Yokoyama; Juntendo Tokyo Koto Geriatric Medical Center (Department of Medicine, Diabetology \& Endocrinology): Kanae Ishida, Noriko Inagaki, Tomio Onuma, Keiko Yamashiro, and Junko Yokota; Juntendo University Graduate School of Medicine (Department of Metabolism \& Endocrinology): Fuki Ikeda, Koji Komiya, Yuko Sakurai, and Motoyuki Tamaki; Kansai Rosai Hospital: Daisuke Azuma, Isao Hayashi, Isao Hayashi, and Tsunehiko Yamamoto; Misaki Naika Clinic: Nobuichi Kuribayashi; Naka Memorial Clinic: Hidenori Isida, Takeshi Osonoi, and Miyoko Saito; Osaka General Medical Center: Masahiro Hatazaki, Ryutaro Kataoka, and Yutaka Umayahara; Osaka Police Hospital: Keisuke Kosugi, Ken'ya Sakamoto, and Kazutomi Yoshiuchi; Osaka University Graduate School of Medicine (Department of Metabolic Medicine): Hideaki Kaneto, Taka-aki Matsuoka, Ken Ohya, and Sae Uno; Sasebo Chuo Hospital: Kazunari Matsumoto, Fumi Mori, and Yoshitaka Mori; and Shiraiwa Medical Clinic: Toshihiko Shiraiwa. Financial support for this study was provided by the Japan Society for Patients Reported Outcome research fund from Mitsubishi Tanabe, Ono, and Novo Nordisk.

\section{References}

[1] Action to Control Cardiovascular Risk in Diabetes Study G, H. C. Gerstein, M. E. Miller et al., "Effects of intensive glucose lowering in type 2 diabetes," The New England Journal of Medicine, vol. 358, no. 24, Article ID 18539917, pp. 25452559, 2008.

[2] Group AC, A. Patel, S. MacMahon et al., "Intensive blood glucose control and vascular outcomes in patients with type 2 diabetes," The New England Journal of Medicine, vol. 358, no. 24, Article ID 18539916, pp. 2560-2572, 2008.

[3] W. Duckworth, C. Abraira, T. Moritz et al., "Glucose control and vascular complications in veterans with type 2 diabetes," The New England Journal of Medicine, vol. 360, no. 2, Article ID 19092145, pp. 129-139, 2009.

[4] The effect of intensive treatment of diabetes on the development and progression of long-term complications in insulindependent diabetes mellitus. The Diabetes Control and Complications Trial Research Group," The New England Journal of Medicine, vol. 329, no. 14, Article ID 8366922, pp. 977-986, 1993.
[5] A. N. Jacob, K. Salinas, B. Adams-Huet, and P. Raskin, "Weight gain in type 2 diabetes mellitus," Diabetes, Obesity \& Metabolism, vol. 9, no. 3, Article ID 17391167, pp. 386-393, 2007.

[6] L. Lundby-Christensen, L. Tarnow, T. W. Boesgaard et al., "Metformin versus placebo in combination with insulin analogues in patients with type 2 diabetes mellitus-the randomised, blinded Copenhagen Insulin and Metformin Therapy (CIMT) Trial," British Medical Journal Open, vol. 6, no. 2, Article ID 26916684, 2016.

[7] E. Yasunari, K. Takeno, H. Funayama et al., "Efficacy of pioglitazone on glycemic control and carotid intima-media thickness in type 2 diabetes patients with inadequate insulin therapy," Journal of Diabetes Investigation, vol. 2, no. 1, Article ID 24843462, pp. 56-62, 2011.

[8] T. Mita, N. Katakami, T. Shiraiwa et al., "Sitagliptin attenuates the progression of carotid intima-media thickening in insulintreated patients with type 2 diabetes: the Sitagliptin Preventive Study of Intima-Media Thickness Evaluation (SPIKE): a randomized controlled trial," Diabetes Care, vol. 39, no. 3, Article ID 26822324, pp. 455-464, 2016.

[9] J. L. Fleg, M. Mete, B. V. Howard et al., "Effect of statins alone versus statins plus ezetimibe on carotid atherosclerosis in type 2 diabetes: the SANDS (Stop Atherosclerosis in Native Diabetics Study) trial," Journal of the American College of Cardiology, vol. 52, no. 25, Article ID 19095139, pp. 2198-2205, 2008.

[10] M. R. Langenfeld, T. Forst, C. Hohberg et al., "Pioglitazone decreases carotid intima-media thickness independently of glycemic control in patients with type 2 diabetes mellitus: results from a controlled randomized study," Circulation, vol. 111, no. 19, Article ID 15883215, pp. 2525-2531, 2005.

[11] Y. Yamasaki, N. Katakami, S. Furukado et al., "Long-term effects of pioglitazone on carotid atherosclerosis in Japanese patients with type 2 diabetes without a recent history of macrovascular morbidity," Journal of Atherosclerosis and Thrombosis, vol. 17, no. 11, Article ID 20686324, pp. 11321140, 2010.

[12] K. Esposito, D. Giugliano, F. Nappo, R. Marfella, and Campanian Postprandial Hyperglycemia Study G, "Regression of carotid atherosclerosis by control of postprandial hyperglycemia in type 2 diabetes mellitus," Circulation, vol. 110, no. 2, Article ID 15197140, pp. 214-219, 2004.

[13] J. Matsubara, S. Sugiyama, K. Sugamura et al., “A dipeptidyl peptidase-4 inhibitor, des-fluoro-sitagliptin, improves endothelial function and reduces atherosclerotic lesion formation in apolipoprotein E-deficient mice," Journal of the American College of Cardiology, vol. 59, no. 3, Article ID 22240132, pp. 265-276, 2012.

[14] M. Arakawa, T. Mita, K. Azuma et al., "Inhibition of monocyte adhesion to endothelial cells and attenuation of atherosclerotic lesion by a glucagon-like peptide-1 receptor agonist, exendin-4," Diabetes, vol. 59, no. 4, Article ID 20068138, pp. 1030-1037, 2010.

[15] N. Ervinna, T. Mita, E. Yasunari et al., “Anagliptin, a DPP-4 inhibitor, suppresses proliferation of vascular smooth muscles and monocyte inflammatory reaction and attenuates atherosclerosis in male apo E-deficient mice," Endocrinology, vol. 154, no. 3, Article ID 23337530, pp. 1260-1270, 2013.

[16] Y.Zeng, C. Li, M. Guan et al., “The DPP-4 inhibitor sitagliptin attenuates the progress of atherosclerosis in apolipoproteinE-knockout mice via AMPK- and MAPK-dependent mechanisms," Cardiovascular Diabetology, vol. 13, Article ID 24490809, 32 pages, 2014. 


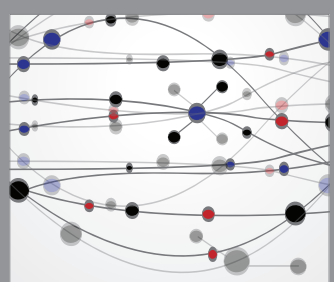

The Scientific World Journal
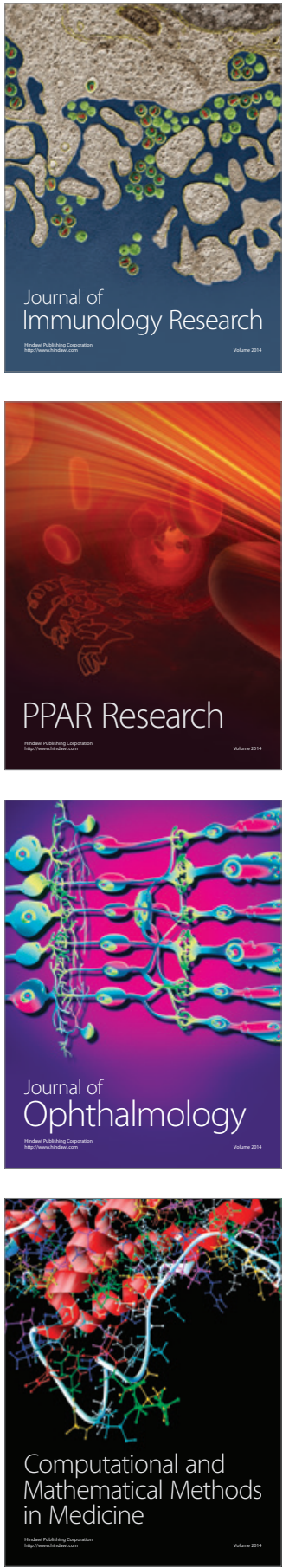

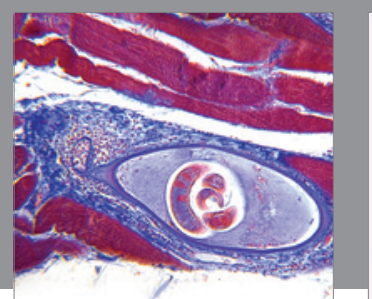

Gastroenterology Research and Practice
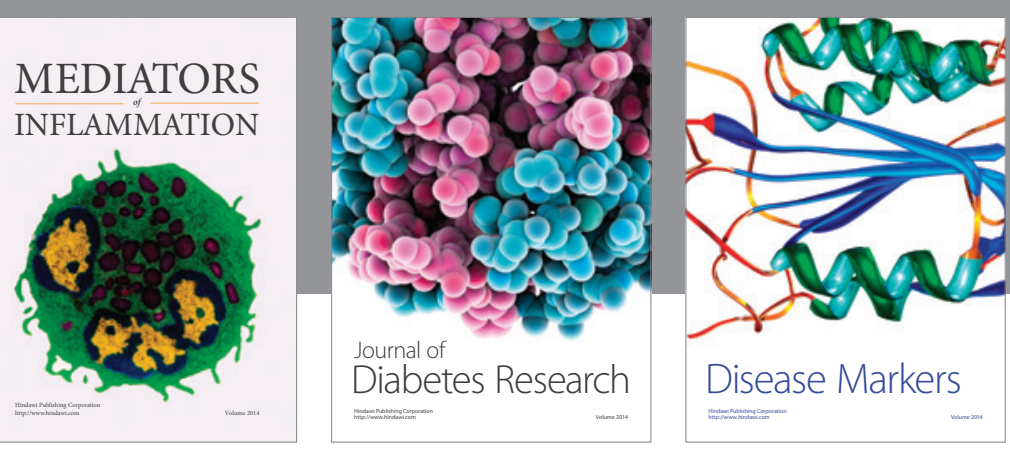

Disease Markers

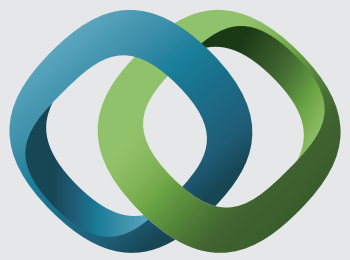

\section{Hindawi}

Submit your manuscripts at

https://www.hindawi.com
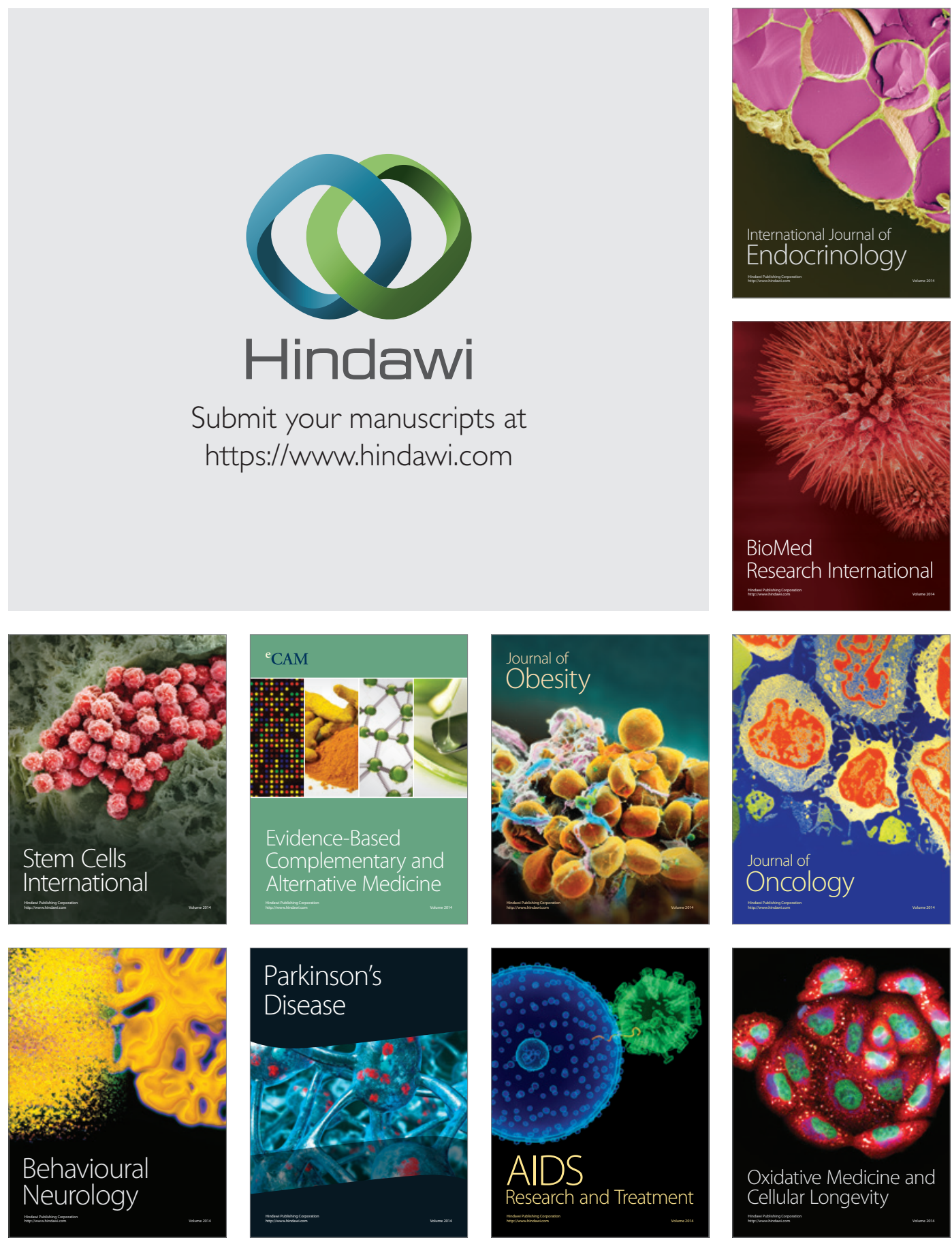